\title{
PENGARUH TINGKAT PENDAPATAN TENAGA KERJA INDONESIA TERHADAP KELANGSUNGAN PENDIDIKAN ANAK DI DUSUN CERET DESA TKI (JENGGIK UTARA)
}

\author{
Suhaili Munahar \\ STIT Palapa Nusantara Lombok-NTB \\ Email. suhaili.elsa@gmail.com
}

\begin{abstract}
This study aims to determine the effect of income levels of TKI to the continuity of education of Children in Ceret Village TKI (North Jenggik). The subject of this study is the parents of students in the village of Ceret, especially families who become migrant workers with a sample of KK people from a population of 150 families. Data collection using Questionnaire in the form of income level, while documentation in the form of data of Villagers and School. The research method that will be used is quantitative descriptive research with correlational approach. While the data collection method used is the questionnaire method and documentation method. Data obtained through data collection was analyzed by statistic method with the formula of product moment rent as follows: From $r$ test value above, where $r$ observation equal to 0,9819 smaller than $r$ table equal to 0,991 With significance level $5 \%$ then $\mathrm{r}$ is significant. So the conclusions of the analysis of this study are: "There is Influence of the level of income of Indonesian labor on the sustainability of children's education in the village of Ceret North Jenggik Village Kec. Montong Gading Kab. East Lombok Year 2017.
\end{abstract}

Kata Kunci : Tingkat Pendapatan, TKI, Keberlangsungan Pendidikan anak

\section{PENDAHULUAN}

Mengingat masih tingginya angka pengangguran di Indonesia baik di tingkat perkotaan maupun tingkat pedesaan, pemerintah bekerjasama dengan Negara lain dalam export tenaga kerja membuka peluang bagi tenaga kerja agar dapat bekerja di luar negeri.

Penopempatan tenaga kerja Indonesia ke luar negeri memiliki berbagai dimensi kepentingan. Bagi TKI bekerja diluar negeri merupakan hak untuk mendapatkan pekerjaan, meningatkan kesejahteraan dan meningkatkan keterampilan bagi pemerintah sendiri, penyelenggaraan itu menjadi alternatif strategis untuk mengurangi jumlah pengangguran di dalam negeri dan memperluas kesempatan kerja bagi masyarakat sekaligus meningkatkan perolehan 
devisa Ne1gara. Pertumbuhan angka tenaga kerja yang tidak seimbang dalam kesempatan kerja yang tersedia, terlebih dalam kondisi perekonomian dewasa ini mengakibatkan pengangguran memerlukan penanganan serius dan mendesak. Penempatan TKI merupakan alternatif strategis untuk mengatasi masalah itu. ${ }^{1}$

Pemerintah dalam hal ini membantu para TKI yang ingin bekerja di luar negeri. Dalam Keputusan Dirjen1 Pembinaan Penemparan Tenaga Kerja berisi tentang petunjuk bagi para TKI yang ingin bekerja di luar negeri. Semakin tingginya laju pertumbuhan penduduk dan tingkat pengangguran Tenaga Kerja Indonesia menyebabkan maraknya tenaga kerja Indonesia yang ingin ke luar negeri untuk mendapatkan hasil (upah) yang memadai. Demikian pula halnya tenaga kerja asal Nusa Tenggara Barat (NTB), khususnya dikecamatan Montong Gading.

Besarnya arus buruh migrant ke luar negeri dari Kabupaten Lombok Tengah yang merupakan salah satu kabupaten di NTB dalam kurun waktu terakhir merupakan bentuk ketidak puasan mereka terhadap apa yang mereka peroleh di dalam negeri. Rendahnya pendapatan mereka sebagai petani dan pedagang menyebabkan mereka berkeinginan untuk bekerja di luar negeri. Meskipun dengan modal pendidikan rendah tapi mampu mendapatkan pekerjaan dengan upah yang lebih memadai.

Persaingan hidup yang semakin ketat, dan semakin meningkatnya kebutuhan yang harus terpenuhi dalam kehidupan sehari-hari. Maka, mau tidak mau bagi masyarakat yang kurang mendapatkan penghasilan pada tempat tinggalnya harus meningglkan keluarganya untuk mencari penghasilan yang lebih memadai. Dewasa ini banyak kita dapati para tenaga kerja Indonesia tidak hanya berasal dari kaum laki-laki (para suami) tetapi banyak juga didapati dari kalangan kaum wanita (ibu-ibu). Hal ini bertujuan untuk memperjuangkan kelanjutan dan kesejahteraan keluarga serta demi masa depan anak-anaknya.

Peluang yang dibuka pemerintah bagi TKI Indonesia merupakan suatu alternatif untuk memecahkan masalah tersebut. Negara-negara yang dituju seperti Malaysia, Saudi Arabia, Korea Selatan dan lain-lain yang membutuhkan tenaga kerja. Perusahaan-perusahaan di Negara tersebut banyak menyerap TKI sebagai buruh pabrik dan ada pula yang diekerjakan sebagai pembantu rumah tangga, walaupun demikian hasilnya lebih memadai dari pada bekerja di dalam negeri dengan modal pendidikan yang rendah.

Para TKI yang bekerja di luar negeri berarti pula meningalkan keluarga dan anak-anaknya dalam kurun waktu yang lama. Sedangkan keberadaan di dalam keluarga sangat dibutuhkan, baik sebagai ibu rumah tangga maupun sebagai pengayom keluarga. Keutuhan keluarga sangat mempengaruhi perkembangan dan kelangsungan study anaknya. Keluarga yang utuh tidak sekedar dalam arti berkumpulnya ayah dan ibu tetapi utuh dalam arti yang sebenar-benarnya yaitu disamping utuh dari fisik juga utuh dalam segi psikis. ${ }^{2}$

\footnotetext{
${ }^{1}$ Depnaker RI, 2007:1

2 Abu Ahmadi, Nur Uhbiyati, Ilmu pendidikan, (Jakarta: Rieneka Cipta,
} 1991). Hal.284 
Menjadi TKI mendatangkan dampak positif yakni dapat memperbaiki perekonomian keluarga, akan tetapi terdapat juga sisi negatif seperti meninggalkan anak-anaknya dalam jangka waktu yang sangat lama. Anak merupakan amanat Tuhan yang harus dijaga dengan baik serta diarah menjadi anak-anak yang mempunyai kepribadian yang baik. Tanpa perhatian sejak dini anak akan berkembang sendirinya tanpa pengawasan dan perhatian orang tuanya.

Diantara salah satu tujuan yang mendasari perginya TKI yang sudah berkeluarga yakni dengan harapan dapat memperlancar kelangsungan sekolah anaknya. Anak (pada usia Sekolah Dasar) sangat membutuhkan pembinaan secara optimal karena pada usia inilah saat yang tepat untuk mendapatkan pembinaan. Untuk melihat lebih mendalam tentang ada tidaknya pengaruh tingkat pendapatan TKI (yang sudah berkeluarga) terhadap kelangsungan pendidikan anak-anaknya, maka peneliti tertarik mengangkat judul penelitian "Pengaruh Tingkat Pendapatan TKI Terhadap Kelangsungan Pendidikan Anak Di Dusun Ceret Desa TKI (Jenggik Utara)

\section{METODE PENELITIAN}

Dalam melakukan penelitian ini, penulis menggunakan pendekatan diskriptif kuantitatif karena data yang akan diperoleh di lapangan lebih banyak bersifat angka-angka dan keterangan. Untuk itu dalam penelitian ini, peneliti memberikan angket kepada informan untuk memperoleh informasi sebannyakbanyaknya atau yang ada kaitannya dengan tingkat penadapatan TKI terhadap kelangsungan pendidikan anak di Dusun Ceret Desa Jenggik Utara Kecamatan Montong Gading Kabupaten Lombok Timur.

Populasi dalam penelitian ini adalah masyarakat Dusun Ceret Desa Jenggik Utara Kecamatan Montong Gading Kabupaten Lombok Timur tahun 2017. Adapun jumlah penduduk yang ada di Dusun Ceret adalah sebanyak 157 Kepala Keluarga (KK). Sampel didasarkan pada Pendapat ahli, apabila subjek penelitian kurang dari 100, lebih baik diambil semua sehingga penelitiannya merupakan penelitian pupulasi. Selanjutnya, jika jumlah subyek penelitian lebih besar, maka dapat diambil antara $10-15 \%$ atau 20-25\% atau lebih. Jumlah penduduk Dusun Ceret Desa Jenggik Utara Kecamatan Montong Gading Kabupaten Lombok Timur tahun 2017 sebanyak 157 Kepala Keluarga (KK), maka sampel dari Peniliti ini adalah diambil sekitar $25 \%$ dari jumlah populasi

\section{Metode Pengumpulan Data}

\section{Metode Angket}

Berdasarkan pertimbangan peneliti tentang metode angket atau kuesioner yang akan dijadikan sebagai alat pengumpul data, maka setelah memperhatikan jenis angket atau kuesioner dari beberapa sudut pandang maupun keuntungannya tersebut di atas, peneliti berkesimpulan bahwa alat pengumpul data yang paling tepat digunakan adalah jenis kuesioner tertutup, langsung dan pilihan ganda.

sebagaimana telah diketahui bahwa skala variable tingkat pendapatan tenaga kerja Indonesia dan kelangsungan studi anak. Jadi kedua variable akan menjadi 
titik perhatian dalam pengumpulan data melalui metode angket ini. Langkah selanjutnya, adalah membuat pertanyaan-pertanyaan angket. Jumlah angket sebanyak 20 butir pertanyaan, karena dianggap semua indicator sudah terwakili dalam dalam 20 butir pertanyaan tersebut. Jumlah pertanyaan jangan terlalu benyak sehingga waktu yang digunakan untuk mengisi hanya kurang lebih satu jam saja yang penting semua indikator sudah terwakili. Angket pertama tentang tingkat pendapatan tenaga kerja Indonesia 10 butir pertanyaan dan angket kedua kelangsungan studi anak 10 butir pertanyaan. ${ }^{3}$

Setiap butir soal disediakan 3 alternatif jawaban, dengan pola penilaian untuk jawaban $\mathrm{a}=$ skor 1 , jawaban $\mathrm{b}=$ skor 2 dan jawaban $\mathrm{c}=$ skor 3 scoring tersebut, diberikan dengan pertimbangan bahwa adanya perbedaan bobot antara pilihan $\mathrm{a}, \mathrm{b}$ dan $\mathrm{c}$. dalam penskalaan ordinal angka-angka yang dipergunakan itu berfungsi menunjuk kepada adanya rank order dalam susunan gejala atau benda. Responden diminta untuk menilai suatu objek atau konsep pada suatu skala yang mempunyai dua adjektif yang bertentangan. Skala bipolar ini mengandung unsur evaluasi (bagus-buruk.......), unsur potensi (besar-kecil, kuat - lemah.......), unsure aktivitas (aktif-pasif, cepat-lambat........).

Dalam metode ini, data yang dikumpulkan adalah data tingkat pendapatan tenaga kerja Indonesia dan kelangsungan pendidikan anak. Pengelompokan hasil penskoran dilakukan dengan memperhatikan skor masing-masing pilihan jawaban dan jumlah petanyaan. Dengamn demikian, jumlah skor perolehan seluruh objek penelitian dikelompokan dari ke 3 kategori tersebut dengan jumlah pancaran yang sama besar.

\section{Metode Dokumentasi}

Dengan demikian dapat diambil suatu kesimpulan bahwa metode dokumentasi adalah suatu metode pengumpulan data dari catatan peristiwa atau laporan tertulis dari suatu kejadian yang telah lalu. Adapun data yang ingin Peneliti peroleh dari metode dokumentasi ini adalah tentang jumlah TKI yang bekerja di luar negeri dikantor Desa.

\section{Jenis Data}

Skala pengukuran yang digunakan dalam penelitian ini skala ordinal, baik untuk variable tingkat pendapatan TKI maupun kelangsungan pendidikan anak.

\section{Sumber Data}

Sumber data yang dipergunakan dalam penelitian ini adalah sumber data primer. Dalam hal ini sebagai sebagai sumber data adalah para narasumber/informan (keluarga TKI), selain data primer peneliti juga memakai data sekunder dimana data penelitian ini juga diperoleh secara tidak langsung dari sumbernya. Artinya data penelitian ini diperoleh melalui pihak atau sarana lain, seperti catatan-catatan tentang data tentang jumlah penduduk serta data tentang jumlah TKI yang ada di Dusun Ceret Desa Jenggik Utara Tahun 2017.

${ }^{3}$ Suharsimi Arikunto, Prosedur Penelitian, Edisi Revisi VI, (Jakarta: Rineka Cipta, 2006). Hal.131 


\section{Identifikasi Variabel}

Untuk mempertegas dan mengetahui lebih jelas variable yang diteliti alangkah baiknya akan diklasifikasikan sebagai berikut: Pertama, Variabel terikat adalah variabel yang dapat dipengaruhi atau variabel akibat. (Arikkunto, 2006: 93) berdasarkan pengertian di atas maka yang menjadi variable terikat dalam penelitian ini adalah tingkat pendapatan TKI di Dusun Ceret Desa Jenggik Utara Kec. Montong Gading Kab. Lombok Timur Tahun 2017. Kedua Variabel bebas adalah variabel yang mempengaruhi atau variabel penyebab ${ }^{4}$. Merujuk dari pendapat di atas maka yang menjadi variabel bebas dalam penelitian ini adalah kelangsungan pendidikan anak TKI di Dusun Ceret Desa Jenggik Utara Kec. Montong Gading Kab. Lombok Timur Tahun 2017.

\section{Teknik Analisa Data}

Dalam usaha untuk dapat menarik kesimpulan akhir dari data lapangan, teknik analisis yang diterapkan merupakan teknik analisis statistik dengan rumus $r$ product momen sebagai berikut:

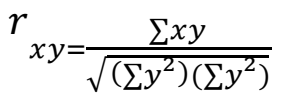

Keterangan:

$r_{x y}=$ Pengaruh Pendapatan Tenaga Kerja Terhadap Pendidikan Anak.

$\sum \mathrm{x}^{2}=$ jumlah Skor Angket Pendapatan Tenaga kerja.

$\sum \mathrm{y}^{2}=$ jumlah Nilai Rata-rata Pendidikan Anak di Sekolah Dasar.

Penggunaan rumus di atas didasarkan pada suatu alasan tertentu sebagaimana yang ada dalam kaidah penggunaannya bahwa: teknik korelasi product moment dipergunakan apabila berhadapan dengan kenyataan berikut ini:

1) Variabel yang kita korelasikan berbentuk gejala atau data yang bersifat kontinyu.

2) Sampel yang diteliti mempunyai sifat homogeny, atau setidak-tidaknya mendekati homogeny.

3) Regresinya merupakan regresi lenier

\section{HASIL PENELITIAN DAN PEMBAHASAN}

\section{Deskripsi Data}

Sebagaimana yang telah dibahas pada bab sebelumnya bahwa metode pengumpulan data yang dipergunakan dalam penelitian ini adalah metode angket dan Dekumen.Metode angket dilakukan pada sejumlah masyarakat untuk mengatahui data tentang pendidikan masyarakat dengan pemberian angket pada setiap pokok permasalahan sebagai variabel $\mathrm{X}$,sedangkan metode dekumen dilakukan pada sejumlah pendidikan anak untuk mengetahui data tentang pendidikan anak di SD yang diambil dari dekumen sebagai variabel Y.sehubungan

${ }^{4}$ Suharsimi Arikunto, 2006: 63 
dengan hal tersebut,maka dalam bab ini akan dideskripsikan hasil angket dan dekumen tersebut,yang telah didapatkan adari responden sebagai sugyek penelitian yaitu pendapatan tenaga kerja dan pendidikan anak di sekolah dasar.

Adapun data penelitian yang deperoleh dari hasil angket dan dekumen ini akan terlihat dalam tabel dikripsi data berikut ini :

Tabel 01.

Hasil Angket Tentang Pendapatan Tenaga Kerja

\begin{tabular}{|c|c|c|c|c|c|}
\hline No & Nama & $\mathbf{L} / \mathbf{P}$ & Umur & Pekerjaan & Skor Angket \\
\hline 1 & Syafi' i & $\mathrm{L}$ & 37 & Tani & 92 \\
\hline 2 & Ahmad & $\mathrm{L}$ & 26 & Swasta & 70 \\
\hline 3 & M.Yusup & $\mathrm{L}$ & 26 & Swasta & 78 \\
\hline 4 & Mariani & $\mathrm{P}$ & 32 & IRT & 88 \\
\hline 5 & Salmah & $\mathrm{P}$ & 36 & IRT & 76 \\
\hline 6 & Murdiono & $\mathrm{L}$ & 39 & Tani & 72 \\
\hline 7 & Safrudin & $\mathrm{L}$ & 35 & Tani & 52 \\
\hline 8 & L.Agus & $\mathrm{L}$ & 29 & Swasta & 56 \\
\hline 9 & Adnan & $\mathrm{L}$ & 27 & Swasta & 53 \\
\hline 10 & Muslim & $\mathrm{L}$ & 26 & Swasta & 74 \\
\hline 11 & Aq.Kurdi & $\mathrm{L}$ & 40 & Tani & 62 \\
\hline 12 & Aq.Rauhun & $\mathrm{L}$ & 38 & Tani & 65 \\
\hline 13 & Mariatun & $\mathrm{P}$ & 28 & IRT & 53 \\
\hline 14 & Nurmin & $\mathrm{L}$ & 32 & Tani & 56 \\
\hline 15 & Sabde & $\mathrm{L}$ & 27 & Swasta & 57 \\
\hline 16 & Alwijaya & $\mathrm{L}$ & 27 & Swasta & 56 \\
\hline 17 & Zurriatun & $\mathrm{P}$ & 29 & IRT & 68 \\
\hline 18 & Selamet Riyadi & $\mathrm{L}$ & 34 & Tani & 73 \\
\hline 19 & Hirman & $\mathrm{L}$ & 26 & Swasta & 57 \\
\hline 20 & Aq.Jumahar & $\mathrm{L}$ & 41 & Tani & 61 \\
\hline 21 & Asarudin & $\mathrm{L}$ & 38 & Tani & 58 \\
\hline 22 & Sumiati & $\mathrm{P}$ & 27 & IRT & 70 \\
\hline
\end{tabular}




\begin{tabular}{|l|l|l|l|l|c|}
\hline 23 & Safarwadi & L & 28 & Swasta & 65 \\
\hline 24 & Umar Wirahadi & L & 25 & Swasta & 63 \\
\hline 25 & Maliki & L & 35 & Tani & 87 \\
\hline 26 & Aq.Salikin & L & 37 & Tani & 82 \\
\hline 27 & Ilhamudin & L & 30 & Tani & 73 \\
\hline 28 & Yulianto & L & 29 & Swasta & 75 \\
\hline 29 & Sabdi & L & 32 & Tani & 69 \\
\hline 30 & Kamaludin & L & 33 & Tani & 58 \\
\hline 31 & Suarni & P & 29 & IRT & 54 \\
\hline 32 & Ema Harianti & P & 25 & Swasta & 66 \\
\hline 33 & Saefullah & L & 24 & Swasta & 72 \\
\hline 34 & Hamdani & L & 32 & Tani & 57 \\
\hline 35 & Taufikkurrahman & L & 28 & Swasta & 68 \\
\hline 36 & Aq.Hilmi & L & 39 & Tani & 55 \\
\hline & Jumlah & & & & $\mathbf{2 3 7 1}$ \\
\hline
\end{tabular}

Tabel 02

Distribusi Data Berdasarkan Kelangsungan Pendidikan Anak

\begin{tabular}{|l|l|l|l|l|c|}
\hline No & \multicolumn{1}{|c|}{ Nama } & L/P & Umur & Pekerjaan & Skor Angket \\
\hline 1 & Syaf' i & L & 37 & Tani & 76 \\
\hline 2 & Ahmad & L & 26 & Swasta & 72 \\
\hline 3 & M.Yusup & L & 26 & Swasta & 67 \\
\hline 4 & Mariani & P & 32 & IRT & 85 \\
\hline 5 & Salmah & P & 36 & IRT & 66 \\
\hline 6 & Murdiono & L & 39 & Tani & 62 \\
\hline 7 & Safrudin & L & 35 & Tani & 53 \\
\hline 8 & L.Agus & L & 29 & Swasta & 65 \\
\hline 9 & Adnan & L & 27 & Swasta & 73 \\
\hline 10 & Muslim & L & 26 & Swasta & 61 \\
\hline
\end{tabular}




\begin{tabular}{|c|c|c|c|c|c|}
\hline 11 & Aq.Kurdi & $\mathrm{L}$ & 40 & Tani & 64 \\
\hline 12 & Aq.Rauhun & $\mathrm{L}$ & 38 & Tani & 57 \\
\hline 13 & Mariatun & $\mathrm{P}$ & 28 & IRT & 68 \\
\hline 14 & Nurmin & $\mathrm{L}$ & 32 & Tani & 51 \\
\hline 15 & Sabde & $\mathrm{L}$ & 27 & Swasta & 58 \\
\hline 16 & Alwijaya & $\mathrm{L}$ & 27 & Swasta & 63 \\
\hline 17 & Zurriatun & $\mathrm{P}$ & 29 & IRT & 63 \\
\hline 18 & Selamet Riyadi & $\mathrm{L}$ & 34 & Tani & 65 \\
\hline 19 & Hirman & $\mathrm{L}$ & 26 & Swasta & 54 \\
\hline 20 & Aq.Jumahar & $\mathrm{L}$ & 41 & Tani & 60 \\
\hline 21 & Asarudin & $\mathrm{L}$ & 38 & Tani & 53 \\
\hline 22 & Sumiati & $\mathrm{P}$ & 27 & IRT & 62 \\
\hline 23 & Safarwadi & $\mathrm{L}$ & 28 & Swasta & 60 \\
\hline 24 & Umar Wirahadi & $\mathrm{L}$ & 25 & Swasta & 74 \\
\hline 25 & Maliki & $\mathrm{L}$ & 35 & Tani & 73 \\
\hline 26 & Aq.Salikin & $\mathrm{L}$ & 37 & Tani & 63 \\
\hline 27 & Ilhamudin & $\mathrm{L}$ & 30 & Tani & 69 \\
\hline 28 & Yulianto & $\mathrm{L}$ & 29 & Swasta & 65 \\
\hline 29 & Sabdi & $\mathrm{L}$ & 32 & Tani & 55 \\
\hline 30 & Kamaludin & $\mathrm{L}$ & 33 & Tani & 66 \\
\hline 31 & Suarni & $\mathrm{P}$ & 29 & IRT & 57 \\
\hline 32 & Ema Harianti & $\mathrm{P}$ & 25 & Swasta & 67 \\
\hline 33 & Saefullah & $\mathrm{L}$ & 24 & Swasta & 64 \\
\hline 34 & Hamdani & $\mathrm{L}$ & 32 & Tani & 65 \\
\hline 35 & Taufikkurrahman & $\mathrm{L}$ & 28 & Swasta & 71 \\
\hline 36 & Aq.Hilmi & $\mathrm{L}$ & 39 & Tani & 80 \\
\hline & \multicolumn{4}{|l|}{ Jumlah } & 2317 \\
\hline
\end{tabular}

Sumber data : Hasil Dokumentasi Tahun 2017

\section{Menguji Signifikasi Product Moment}

Dari hasil perhitungan ternyata nilai $\mathrm{r}$ xy yang diperoleh dalam penelitian ini adalah 0,9819 sedangkan nilai $\mathrm{r}$ xy dalam table dengan taraf signifikasi $5 \%$ 
dan $\mathrm{N}=36$ adalah 0,991 Kenyataan ini menunjukan bahwa nilai $\mathrm{r}$ xy yang deperoleh dalam penelitian ini adalah lebih besar dari pada nilai $r$ xy dalam $r$ table.Sehingga korelasi $\mathrm{r} x y$ dinyatakan signifikan.

\section{Menarik Kesimpulan}

Dari pengujian nilai $\mathrm{r}$ di atas, dimana $\mathrm{r}$ observasi sebesar 0,9819 lebih kecil dari $\mathrm{r}$ table sebesar 0,991 dengan taraf signifikansi $5 \%$,maka $\mathrm{r}$ xy dinyatakan signifikan. Maka kesimpulan analisis dari penelitian ini adalah : " Ada pengaruh tingkat pendapatan tenaga kerja Indonesia terhadap pendidikan anak di dusun Ceret Desa Jenggik Utara Kec. Montong Gading Kab. Lombok Timur Tahun 2017".

\section{Pembahasan}

Dari hasil pengujian hipotesis menunjukan bahwa : "Ada pengaruh tingkat pendapatan tenaga kerja Indonesia terhadap pendidikan anak di dusun langgalawe desa Aik Bukak Kecamatan batukliang Utara Kabupaten Lombok Tengah tahun 2011.Berdasarkan hasil temuan ini,ada beberapa pemikiran dari peneliti tentang pengaruh tingkat pendapatan tenaga kerja terhadap pendidikan anak di dusun Ceret Desa Jenggik Utara Kec. Montong Gading Kab. Lombok Timur Tahun 2017, signifikan.

Pertama, pendapatan tenaga kerja Indonasia terhadap pendiDikan anak di dusun Ceret Desa Jenggik Utara Kec. Montong Gading Kab. Lombok Timur Tahun 2017sangat ditentukan oleh pendidikan masyarakat terutama orang tua dalam mendidik anaknya. Jika pendidikan orang tua atau masyarakat itu tinggi, maka kecendrungan anak dalam pendidikan juga akan tinggi,yang pada akhirnya dapat menurunkan tingkat pertumbuhan penduduk suatu desa itu sendiri.Begitu juga sebaliknya,jika pemberian pendidikan masyarakat terhadap pendidikan anak di dusun Ceret Desa Jenggik Utara Kec. Montong Gading Kab. Lombok Timur Tahun 2017 itu rendah,maka kecendrungan pertumbuhan pendudukan di Desa itu juga akan rendah,sehingga akan sulit mendapatkan penurunan jumlah penduduk yang optimal. Dalam kaitannya dengan pendapatan tenaga kerja, maka pihak pemerintah memahami akan pentingnya penyuluhan terutama dalam pengatahuan tentang Pendidikan anak usia dini pemberian apersepsi kerna banyak factor yang turut menentukan, antara lain : Tingkat pendapatan orang tua atau masyarakat,tenaga penyuluh yang terjun langsung di masyarakat,manajemen yang baik,peran serta orang tua dan masyarakat, dan sebagainya.

Kedua, kita sadar bahwa kelangsungan pendidikan anak usia dini akan membawa efek samping yang lebih banyak,membimbing dan memberikan pengertian pada anak bukan saja merupakan tugas pemerintah,melainkan juga tugas orang tua atau keluarga di rumah.Jika kita berhitung aktivitas anak di sekolah paling maksimal adalah 6 jam,dan selebihnya adalah di rumah. Jadi demikian,lingkungan keluarga juga sangat menentukan sikap anak dalam menentukan hidup anak. 


\section{Kesimpulan}

Berdasarkan hasil analisis data dan pembahasan dapat disimpulkan bahwa "Ada pengaruh tingkat pendapatan tenaga kerja Indonasia terhadap pendidikan anak di dusun Ceret Desa Jenggik Utara Kec. Montong Gading Kab. Lombok Timur Tahun 2017.

\section{DAFTAR PUSTAKA}

Abu Ahmadi, Nur Uhbiyati, Ilmu pendidikan, Jakarta: Rieneka Cipta, 1991.

A. Muri Yusuf, Pengantar Ilmu Pendidikan, Jakarta: Rajawali Pers, 1996.

Depdikbud, Human Development and Education, Jakarta, Depdikbud, 1995.

Depnaker Transmigrasi RI. Nomor 39 Tahun 2004. tentang Penempatan dan Perlindungan Tenaga Kerja Indonesia di Luar Negeri: 7. Fuad Ihsan, Dasar-dasar Kependidikan, Jakarta: PT. Rineka Cipta, 2005. Http://www.scribd.com/doc/ dikutip tanggal 7 Mei 2009

John Dewey dalam Abu Ahmadi, Nur Uhbiyati, Ilmu Pendidikan, Jakarta: Rineka Cipta, 1991.

Laeli, Menggagas Fiqh Sosial, Bandung: Mizan, 1995.

Lexy J. Moleong, Metodologi Penelitian Kualitatif, Bandung: Remaja Rosdakarya, 2004.

Lincolin, Arsyad, Ekonomi Pembangunan, Yogyakarta, Juni, 2004. Bagian penerbitan sekolah tinggi ilmu ekonomi.

Margono, Metodologi Penelitian Pendidikan, Jakarta: PT. Rineka Cipta, 2004.

Miftahul Huda dan Muhammad Idris, Ar-Ruzz, Nalar Pendidikan Anak,Media, Jogjakarta, Oktober 2008.

Mulyadi Sabri, Ekonomi Sumber Daya Manusia, Raja Grafindo Persada, Jakarta. 2003.

Ngalim Purwanto, Psikologi Pendidikan, Bandung: PT. Remaja Rosdakarya, 2007.

Nurkencana, Wayan dan PPN Sumartana, Evaluasi Hasil Belajar, Surabaya: Usaha Nasional, 1990.

Pengantar Dasar-dasar Kependidikan Tim Dosen FIP-IKIP Malang, Usaha Nasional Jl. Praban No. 55 tahun 1998, Surabaya.

Ruslan H. Prawiro. Ekonomi Sumber Daya, Alumni, Bandung, 1990.

Slameto, Belajar dan Faktor-faktor yang Mempengaruhinya, Jakarta: Rineka Cipta, 2003.

Suharsimi Arikunto, Prosedur Penelitian, Edisi Revisi VI, Jakarta: Rineka Cipta, 2006.

Syaiful Bahri Djamarah, Pola Komunikasi Orang Tua dan Anak dalam Keluarga Jakarta: Rineka Cipta, 2004.

Syaiful Bahri, Pola Komunikasi Orang Tua dan Anak dalam Keluarga, Jakarta: Rineka Cipta, 2004.

Undang-Undang RI Nomor 14 Tahun 2005, Undang-Undang RI Guru dan Dosen Beserta Penjelasannya, Jakarta: Cemerlang, tt.

Winarno Surachman, Metode Research Pendidikan, Yogyakarta: Andi Offset, 1997. 